\title{
PROSPECTS FOR CELLULAR MUTATIONAL ASSAYS IN HUMAN POPULATIONS
}

\author{
MORTIMER L. MENDELSOHN
}

\section{Prepared for the Proceedings \\ of the \\ Symposium on "Assessment of Risk from Low \\ Level Exposure to Radiation and Chemicals:}

A Critical Overview"

H.:1d on May 20-23, 1984

Brookhaven National Laboratory,

Uptor, Long Island, New York

June 29, 1984

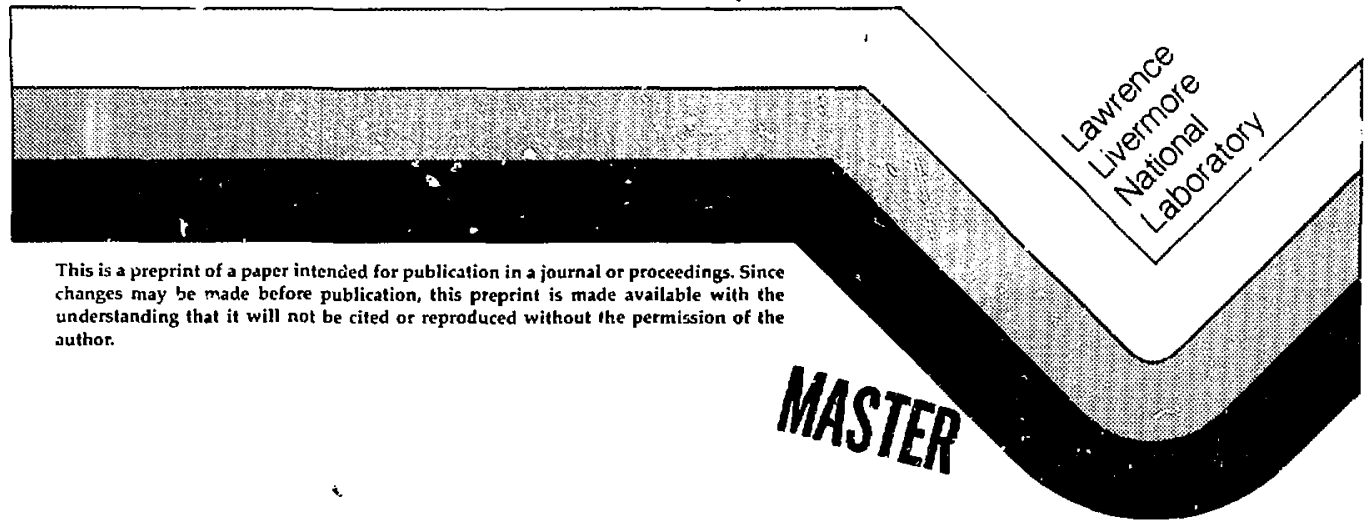

OSTRBOUTIOH OF THS BOCUMENT IS UMLIMITE 
PROSPECTS FOR CELLULAR MUTATIONAL ASSAYS IN HUMAN POPULATIONS

\author{
Mortimer L. Mendelsohn, M.D., Ph.D. \\ Biomedical Sciences Division, \\ Lawrence Livermore National Laboratory \\ Livermiore, CA, 94550
}

Practical, sensitive, effective, human, cellular assays for detacting somatic and gezminal mutations would have great value in environmental mutagenesis and carcinogenesis. When available, such assays should allow us to fill the void between human mutagenicity and the data that exist from short-term testa and from mutagenicity in other species. We will be able to validate the role of somatic wutation in carcinogenesis, to identify germinally active human environmental factors, to integrate complex suixture and environmental effects in the humsn subject, and to identify people who are hyper-susceptible to genetic injury. Human cellular mutational assays, particularly when combined with cytogenetic and heritable mutational methods, promise to play pivotal roles in estimating the risk from low-dose radiation and chemical exposures. These combined methods avoid extrapolations of apecies and dose, and may be sensitive enough and credible enough to permit politically, socially and scientifically acceptible risk management.

Cytogenetic methods Blready have wide applicability to the human (Evans, this volume), and heritable mutational measurements are undergoing an extensive epidemiological trial in Japan (Neel, this volume). However, we presently have no validated,generally accepted methods for human somatic or germinal cellular mutational assays. Bleak as this sounds, I believe the technology is almost available and that we are on the verge of having several promising cellular mutational methods for human application. 
Somatic and germinal assays have one enormous advantage over heritable assays. As is clear from the studies of the Hiroshima and Nagasaki populations (Neel, this volune), observable heritable genetic changeg at any particular locus occur with great rarity. To find sufficient mutational events for measurement of rate, one must study millions of offapring, millions of loci, or some combination of the two. The expectation is that somatic and germinal mutation rates wi?l be similarly $8 \mathrm{mall}$, but for these measurements any one person can provide the millions or billions of cells needed to estimate a mutacion rate. The subjecss (ie. the cells) thus are readily and suftaciently available; the challenge is to detect the rare, one-in-atailition events at the cellular level and to have good assurance that the events represent mutational phenomena.

Letection strategies at the cellulai level can be baged on four types of changes:

* alteration in behavioral phenotype, such as drug resiatance.

* alteration in gene product, such as a modified protein.

* alteration or loss of a messenger RNA.

* alteration or 1088 of a DNA sequence.

The further down the list one goes, the closer one is in principle to a verifiable mutational event; however, to my knowledge the RNA and DNA based methods are not yet available for single cell application. To identify RNA and DNA changes would require methods that detect 1088 of a single sequence or gain of a minimally-deviant single-copy sequence in a single cell. Assays based on changes in behavioral phenotype and in gene product seem more feasible with present technology and are discussed below.

\section{HPRT SOMATIC CELL MUTATION BASED ON 6-THIOGUANINE RESISTANCE}

R.J.Albertini has pioneered the development of assays in human peripheral blood lymphocytes based on resistance to 6-thioguanine. In the original assay (Strauss and Albertini, 1979), freshly drawn lymphocytes were exposed to

phytohemagglutinin (a mitogen), 6-thioguanine (a purine analogue that is cytotoxic to cells attempting DNA synthesis in the presence of effective levels of the enzyme HPRT (hypoxanthine phosphoribosyltransferase)), and tritiated thynidine (a label to detect those cells successfully carrying out DNA synthesis). 
Autoradiography was used to count both the rare, resigtant, inymidine labelled cells, and the cells at risk (based on labelled celle in cultures not exposed to 6-thioguanine).

Encouraged by early results, Albertiai and his colleagues collected a sizable body of cata using this assay (Albertini, 1982). They observed back乃romd levels which did not change with age, increased levelo in curcer patients before and after cancer therapy, and increased levels after PUVA therapy. Instability of background levels, and consistently high variant frequencies with occasional values as high as one variant per 100 cells at risk led to the suapicion that the assay was detecting phenocopies as well as mutants. One source of phenocopies seemed to be circulating cells comitted to DNA synthesis before exposure to mitogen. These cells and the excessively high variant frequencies were eliminated by introducing a cryopreservation step into the assay.

At this point in the evolution of the method, sufficient doubt had been cast on the mutational validity of the autoradiographic endpoint to make Albertini refocus his efforts toward a clonogenic version of the assay (Albertini et al., 1982). He was able to clone single cells in microwell cultures at an efficiency up to $50 \%$ using a crude $T$-cell growth factor. This lea to a dilution assay which could be used both to estimate the frequency of thioguanine resistant cells, and to support the mutational nature of the phenotype by demonstrating the corresponding HPRT enzyme deficiency in the resistant clones. Albertini is now in a position to validate the mudified autoradiographic assay or to use the cionogenic assay, and to redo and continue on with his epideniologic applications of the methods.

Several other laboratories are pursuirg these approaches with mixed success. Amneus et al.(1982) at the University of Upsalla have incorporated into the original Strauss and Albertini procedure the methoo of flow cytometric sorting to concentrate late $S$ and $G 2$ cells prior to autoradiography. This facilitates counting and eliminates some sources of phenocopies. Their recent results (Amneus et al.,1984) suggest that the variant ceils early after a mutagenic insult are predominantly due to DNA leaions which interfere witn enzyme production. As the lesions are repaired, these variants disappear and are replaced by less frequent, presumably-stable mutants. This group feels that the short-term autoradiographic assay in human peripheral blood lymphocytes may be useful for estimating DNA damage but not mutation. On the other hand, Morley et al. $(1982,1983)$ have described autoradiogrephic and clonogenic assays which they believe successfully detect HPRT mutarions in human peripheral blood lymphocytes. J.Evans and colleagues in Edinburgh (this 
volume) have recently produced credible radiation dose-responses in vitro in human lymphocytes using a clonogenic version of the HPRT assay. Similarly, I. Jones et $a l .(1984)$ at Livermore have a clonogenic assay that is working well with mouse splenocytes mutagenized in vivo.

In spite of the difficulties, it seems likely that some form of IIPRT assay will be available for general application in the near future. Assays for other genes involving drug resistance are also possible, although this approach is inherently limited for human application to those genes functioning effectively as single copies (ie.only to genes on the $X$ chromosome) or to dominant selectable markers such as diptheria resiotance.

\section{HEMOGLOBIN SOMATIC CELL MUTATION ASSAY}

In 1976, Papayannopoulou et al at the University of Wasnington developed a monospecific polyclonal antibody to $\mathrm{Hb} S$ (sickle hemoglobin), showed that the fluorescent antibody could be used to identify sickle trait erythrocytes in smears, and raised the possibility of using this as an assay for gickle-like somatic mutations in erythrocyte precursors. This general strategy of using known mutated gene products to generate immunologically specific reagents to detect new cellular mutant has broad potential applicability in somatic mutagenesis.

The same group developed a variety of similar immunologic probes to hemoglobins with single amino-acid substitutions (eg Hb C, Papayannopoulou e.t al.,1977), as well as probes to hemoglobin frame shift variants ( $\mathrm{eg}$ Hb Wayne and Hb Cranston, Stamatoyannopoulos et al., 1980). They showed that the rate of appearance of thb $S$ and $C$ bearing erythrocytes in normal adults was on the order of one in 10 million, and that thie rate increased after cancer chemotherapy. However, for then to make such determinations manually by fluorescence microscopy was extremely arduous, requiring one person-month to count a single sample.

In collaboration with the Washington group, a team from the Lawrence Livermore Nationsl Laboratory attempted to automate the $\mathrm{Hb} S$ method using flow cytometry (Bigbee et al., 1981). They developed a way to stain erythrocytes in suspension, and to examine one million erythrocytes per second. However, direct application was prevented by false-positive events occurring at roughly one per one-hundred thousand erythrocytes. By using flow sorting to concentrate fluorescent cella, they were able to cc firm the original frequencies of occurence of variarits, but found the results too variable for quantitative or epidemiologic i spication. 
Continuing independently, the Livermore group (Bigbee et al., 1983; Jensen et al., 1964) has developed a suite of monoclonal, monospecific antibodies that recognize a variety of single-base change, single-amino-acid substitutions $i$ human, rouse and monkey hemoglobins. They have also developed improved methods of fixation that provide better antibody staining, more durable cells, and cells suitable for flow cytometric counting by scatcered light. The problem of false positive signsls continues to plague the method but is now reduced by a factor of 10 . With the present methods, in reconstruction experiments it is possible by flow sorting to retrieve 88 antibody labelled cells

(coefficient of variation, $10 \%$ ) from a mixture of 100 labelled and one billion unlabelled cells. Further developments using human, mouse and perhaps monkey blood sauples is underway using the partially automated sorting method, as are attempto to fully automete the procedure.

An important limitation of this method has to do with its incredible resolution. Much as one way want the flexibility to measure single, specific, base changes (ie the ultimate resolution of a genetic method), certain mutagens (such as ionizing radiation) way be very inefficient at produciag such small lesions. In addition, the smaller the target size, the raxer the expected cuicome. As mutant frequencies drop one or several orders of magnitude below one per million, it becomes increasingly difficult to detect the rare events or to have a large enough fopulation of precursor cells at risk to measure the frequency of variants properly.

\section{GLYCOPHORIN SOMATIC CELL MUTATION ASSAY}

An alternative to the imitations of the hemoglobin-based assay would be an immunological assay that recognizes gene-loss mutations at the cellular level. Prior attempts at such assays are thought to have failed to detect true mutational events (Atrood and Petter, 1961), perhaps due to the high prevalence of phenocopies mimicking the desired genetic change. This problam can apparently be avoided in a setting where two allelcs are codominantly expressed and can be seperately detected in the same cell. The loss of either allele can then be detected in cells in which the other allele is still functioning normally and serves as a physiological control. Glycophorin-A in erythrocytes appears to be just such a system.

Human glycophorin-A is a 131 amino acid, trans-membrane sialoglycoprotein that codes for the $M$ and $N$ serocypes. $M$ individuals have a serine and glycine respectively at che 1 and 5 position, counting from the amino-terminal external end. N individuals have a leucine and glutamic acid at these same 
positions. Otherwise the two molecular types are identical. Each allele on average produces roughly 250,000 copies per erythrocyte whether in a homozygous or heterozygous configuration. The principle of the somatic mutation method is to label $M$ and $N$ independantly with monoclonal antibodies carrying different fluorophores. In heterozygous individuala, every normal erychrocyte should show both fluorescent colors. A mutation inactivating one allele would result in erythrocytes lacking the $M$ or $N$ antigen. Such cells will fail to bind one of the monoclonal antibodies while expressing the second nomally. Symmetry is expected. Thus the rate of variants seen for one color should be similar to that seen for the second,

Bigbee et al.(1983, 1984) have produced a series of monoclonal antibodies againgt the $M$ and $N$ glycophorins, as well as several public antibodies that recognize both forms squally. When the antibodies are fluorescently labelled they show high affinities to glycopherin in fixed erythrocytes in suspension. The flow cytometric signals of such erythrocytes typically have coefficients of variation of $12 \%$, with peak means that vary from one person to the next by a coefficient of variation of os little as 3\%. The Liverwore studies have confirmed that the expression of the two alleleg is quantitatively independent.

To date, putative mutants have been sought using only half of thi assay. That is, the antity antibody has been used in conjunction with one of the public antibodies. The method in this limited form works well, finding roughly 8 variants per million erythrocytes in nomal individusls. A preliminary trial on patiencs undergoing chemotherapy found average rates increaged $h_{j} 100 \%$, with one individual increased by $800 \%$. The full assay with both antibodies is now being tested and hopefully will proviut confirmation through symetry that the variants are indeed mutants.

One of the Livermore anti-M antibodies is able to recognize glycophorin-Mc, a rare allele which differs from $N$ only in the presence of a serine at position 1 . This antibody is thus discriminating $M$ from $N$ by the difference in the single terminal amino acid. It could be used to detect single amino-acid substitutions in NN homozygotes, and should be comparable in resolution and performance to the hemoglobin reagents. Thus with the set of antibodiey now in hand, it may be possible to measure both point mutation and gene $108 \mathrm{~s}$ at the glycophorin locus.

\section{LDH-X SPERM CELL MUTATION ASSAY}

The same techniques described for somatic cells can in principle be applied to germinal cells, although presently it is 
only mature operm that can be readily sampled in the human. Ansari, Baig and Molling (2980) have described what way be the prototype for ouch methods. They immunized mice with rat LDH-X, a form of lactate dehydrogenase that is localized opecifically to germinal cells. Highly apecific polyclonal antibodies were produced. These of course recognized rat sperm, but also had the ability to recognize roughly one per million mouse sperm. The presumption is that the recognized mouse sperm were expressing an LDH-X gene which mutated to the rat genocype at a single site. The sperm were identified by staining or fluorescence of their midpiece. A dose-response curve to procarbazine treatment of the mice gave very convincing results.

Unfortunately Malling has been unable to reproduce these results and has exhausted his supply of the active antibody. Nevertheless, the potential remains to apply similar techniques to human sperm. Whether such germinal methods will or will not be predictive of heritable mutation remains to be seen, but whatever the outcome, cellularly based methods in sperm should provide an important insight into agents capable of reaching the testis, activating appropriately, and causing the expression of abnormal gene products.

\section{DISCUSSION}

No one of the methods discussed above is actually available today for application to human testing, yez I hope it is clear why I am optimistic that such wethods should goon be at hand. Obviously they will need extencive elaboration before general application. Validation will be especially important since the approaches outlined for: the most part do not measure mutations directly. Validation will presumably be by a variety of consistency tests in human subjects and model systems. In some situations it may be possible to clone cells and validate directly. In others, such as the methods involving anucleate erythrocytes, cloning is out of the question. For the erythrocytic methods, the best one can hope for is that isolation of the variant cells will allow biochemical confirwation of the expected electrophoretic or other mutational changes in the involved proteins.

The full extension of these methods requires a great deal more than the few isolated examples given in this presentation. Ideally one would want methods that are sengitive to all types of DNA lesions, including base substitutions in all four bases, frame shift lesions, and small and large deletions, inversions or translocations. A fully representative spectrum of genes should be included, as well as aroad and relevant sampling of tiosueg and cells. For somatic mutation there is an expectation that an 
elevated rate would be predictive of cancer risk. But would a high rate in erythrocytes predict only polycythemia? Or would erythrocytic mutations also predict cancer in a variecy of ocher tissues and organs?

We must underatand well the kinetics of how mutants appear and disappear in cell populations. These kinetics will involve turnover of cell compartments, the maturity of the initially mutated cell, and possible selective disadvantage or advantage for the mutarit phenotype. A test gystem with short duration (i.e. short memory or short integration time) would be best suited for studying acute exposure situations. Intermediate to long-term memory would be best for studying the effects of occupations, life styles, or geographical factors, or for searching aut repair defective individuals. Finally it will be important to understand better what the time domain means to the rate calculation. Is the relevant parameter mutations per cell cycle, mutations per hour, gutations per generation, or some mixture of these? How differenty is this expressed in species with different lifetimes and different body sizes?

Clearly much remains to be done to develop the methods and to gain some understanding of their application. In spite of this, direct resting in humans remains in my view the single most tractable way to approach the low-dose risk problam for carcinogenesis and mutagenegis. I hope the resources and scientific strengtho will be available to make it happen quickly and effectively.

\section{ACKNOWLEDGEMENTS}

Work perfermed under the auspices of the V.S. Department of Energy by the Lawrence Livermore National Laboratory under contract number $\mathrm{k}-7405-\mathrm{ENG}-48$.

\section{REFERENCES}

Albertini, R.J., 1982, Studies with T-lymphocytes: An approach to human mutagenicity monitoring, In: "Banbury Report 13, Indicatora of Genotoxic Exposure", B.A.Bridges, B.E.Butterworth, and I.B.Weinstein, eds., Cold Spring Harbor Lab., PP 393-412.

Albertini, R.J.., Cast.le, K.L., and Borcherding, W.R., 1982, T-cell cloring to detect the mutant 6-thioguanine-resistant 1 ymphocytes present in human peripheral blood, Proc. Natl. Acad. Sci., USA, 79:6617-6621. 
Ameus, H., Mattaon, P., and Fellner-Feldegg, H. 1984, Peraons communication,

Amneus, H., Matsson, P., and Zetterberg, G., 1982, Human lymphocytes resistant to 6-thioguanine: Restrictions in the use of a test for somatic mutations arising in vivo studied by flow-cytometric enrichment of resigtant cell nuclei, Mut. Res. 106:163-178.

Ansari, A.A., Baig, M.A., and Malling, H.V., 1980, In vivo germinal mutation detection with "monospecific" antibody against lactate dehydrogenase-x, Proc. Nacl. Acad. Sci., USA, $7 ;: 7352-7356$.

Atwood K.C. and Petter, F.J., 1961, Erythrocyte automosaicism in some persons of known genotype, Science 134: 2100-2102.

Bigbee, W.L., Branscomb, E.W., Weintraub, H.B., Papayannopoulou, Th., and Stamatoyannopou?os, G., 1981, Cell sorter immunofluorescence detection of human erythrocytes labeled in suspension with antibodies specific for hemoglobin $S$ and C, J. Inmunol. Methods, 45:117-127.

Bigbee, W.L., Langloia, R.G., Vanderlasn, M. and Jensen, R.H., 1984, Binding specificities of eight monoclonal antibodies to human glycophorin $A$ : Studies using $M^{C} M$ and $M^{k} E_{n}(U K)$ viriant human erythrocytes and $M$ - and $M N^{V}$-type chimpanzee erythrocytes, J. Immunol. Submitted.

Bigbee, W.L., Vanderlaan, M., Fong, S.S.N., and Jenten, R.t., 1983, Monclonal antibodies specific for the $M-$ and $N$-forms of human glycophorin A, Molecular Immunol. 20:1353-1362.

Evans, J. This volume.

Jensen, R.H., Bigbee, W.L., and Branscomb, E.H., 1984, Somatic mutations detected by imunofluorescence and flow cytometry, in: "Biological Dosimetry", W. Eisert and M.L. Mendelsahn, eds., Springer-Verlag, Heidelberg, pp 161-170

Jones, I.M., Burkhart-Schultz, K., and Carrano, A.V., 1984, Cloning of thioguanine resistant lymphorytes for measurement of in vivo mutation in the mouse. Manuscript in preparation.

Morley, A.A., Cox, S., Wigmore, D., Seshadri, R., and Dempsey, J.L., 1982, Enumeration of thioguanine-registant lymphocytes using autoradiography, Mut. Res. 95:363-j75. 
Morley, A.A., Trainor, K.J., Seshadri, R., and Ryall, R.G., 1983,

Mejurement of in vivo mutations in human lymphocytes,

Nature $302: 155-156$.

Nee l, J. This volume.

Papayannopoulou, Th, McGuire, T.C., Lim, G., Garzel, E., Nute, P.E., and Stamatoyannopoulos, G., 1976, Identification of haemoglobin $S$ in red cells and normoblasts, using fluorescent anti-Hb $S$ antibodies. Brit. J. Haematol. $34: 25-31$,

Papayannopoulou, Th., Lim, G., McGuire, T.C., Ahern, V., Nute, P.E., and Stamatoyannopoulos, G., 1977, Use of opecific fluorescent antibodice for the identification of hemoglobin C in erythrocytes, Amer. J. Hemat. 2:105-112.

Stamatoyannopoulos, G., Nute, P.E., Papayannopoulou, Th., McGuire T.C., Lit, G., Bunn, H.F., and Rucknagel, D., 1980, Development of a somatic mutation screening sygtem 1 aing $\mathrm{Hb}$ mutants. IV. Successful detection of red cells containing the human frameshift rutants Hb Wayne and Hb Cranston using monospecifis fluorescent antibodies, Am. J. Human Genetics $32: 484-496$.

\section{DISCLAIMER}

This report was prepared us an account of work sponcosed by an agency of the United States Government. Neither the United States Jovernment nor any agency thereof, nor any of their employees, makes any warranty, express or implied, or assumes any legal liability or responsibility for the accuracy, completeness, or uxefuluess of any information, apparalus, ploduct, or process disclosed, or reprasents that its use would not infringe privately ouped rights. Reference herein te any specific commercial product, process, or service by trade name, trademark, manufacturer, or otherwise docs not necessarily constitute or imply its endorsement, recommendation, or favoring by the United States Government or any agency thereor. The views and opinions of authors expressed herein do not nrcessarily state or reflect those of the United States Government or any agency thercul. 